\title{
ESTUDIOS
}

\section{La antropología de Gaudium et spes}

\section{Mathias Nebel'}

Resumen: El autor, teniendo en cuenta la sobreabundancia de estudios aparecidos hasta la fecha, y especialmente en el cincuentenario de la constitución pastoral conciliar Gaudium et spes, que han fijado la "historia de la redacción" y de los debates en los años conciliares, y puesto quevivimos y pensamos en contextos históricos muy diferentes, adopta una perspectiva fenomenológica y hermenéutica. El fracaso del propósito de diálogo con el mundo que ha intentado la Iglesia, a diferencia de lo que ocurría en los años 60 del siglo pasado, define la actual situación. Siendo el tono y el argumento del documento conciliar explícitamente teológico, su coherencia también lo es abiertamente y no pretende en ningún momento entablar un diálogo desde la razón secularizada, la lectura y recepción que sin embargo se han hecho por muchos para entablar un diálogo desde la razón natural se ha convertido en la historia de una infidelidad, pues los padres conciliares adoptaron una perspectiva netamente teológica para entablar ese diálogo con el mundo, ya que el argumento teológico debe ser propuesto como parte de la razón pública, pues, aunque su racionalidad sea transcendente no deja de ser comunicable e inteligible por otros interlocutores. El autor sospecha que el "fracaso" del diálogo secularizado puede deberse a la "autocensura" del discurso religioso en el terreno de lo público. En la segunda parte el autor subraya la necesidad del juicio moral -y critica su ausencia en el discurso público y en la ética teológica-, juicio necesario para poder humanizar el mundo. Sólo mediante el discernimiento ético abierto por el discurso teológico sobre el mundo podremos dar razón del sentido de nuestra esperanza, lo que plantea la necesidad de rehabilitar el valor y el status de ese juicio ético.

Palabras clave: antropología, diálogo, discernimiento, juicio ético, racionalidad teológica, razón secular, status social de la Iglesia.

Fecha de recepción: 3 de julio de 2017 .

Fecha de aceptación definitiva: 25 de octubre de 2017.

\footnotetext{
${ }^{1}$ Institut Catholique, París y Fondation Caritas in veritate, Ginebra (Suiza) - Chambéry (Francia).
} 


\section{The anthropology of Gaudium et spes}

Abstract: The author, taking into account the overabundance of studies published up to now, and especially in the fiftieth anniversary of the Conciliar pastoral constitution Gaudium et spes, which have fixed the "history of the redaction", and of the debates in the Conciliar years, and given that we live and think in very different historic contexts, adopts a phenomenological and hermeneutic perspective.

The failure of the purpose of dialogue with the world, intended by the Church, contrary to what happened in the Sixties of last century, defines the present situation.

The tone and the argument of the Conciliar document being explicitly theological, its coherence is also equally openly theological, and itdoes not claim, in any moment, to establish a dialogue from the secularized reason, the reading and reception that nevertheless have been made by many to establish a dialogue from the natural reason, has turned into the history of an infidelity, because the Conciliar Fathers adopted a genuinely theological perspective, in order to establish that dialogue with the world, given that the theological argument must be proposed as part of the public reason, because, even if its rationality be transcendental, it does not fail to be communicable and understandable by other interlocutors.

The author suspects that the "failure" of the secularized dialogue can be because of the "self-censorship" of the religious discourse in the field of the public entity. In the second part, the author emphasizes the need of the moral judgment, -and criticizes its absence in the public discourse and in the theological ethics-, a necessary judgment so as to be able to humanize the world.

Only through the ethical discernment, opened by the means of the theological discourse about the world, shall we be able to give

\section{L'anthropologie de Gaudium et spes}

Résumé: En tenant compte de la surabondance d'études similaires apparues jusqu'à nos jours, et particulièrement lors du cinquantenaire de la constitution pastorale conciliaire Gaudium et Spes, qui ont fixé «'histoire de la rédaction» ainsi que des débats dans les années conciliaires, et puisque nous vivons et que nous pensons de nos jours dans un contexte historique très différents, l'auteur adopte une perspective phénoménologique et herméneutique.

L'échec de la tentative de dialogue avec le monde essayée par l'Église, à différence de ce qui se passait dans les années 60 du dernier siècle, définit la situation actuelle.

Le ton et l'argument du document conciliaire étant explicitement théologique, sa cohérence l'est aussi ouvertement, et ne prétend à aucun moment établir un dialogue depuis la raison sécularisée. Cependant, la lecture et la réception faites par beaucoup afin d'établir un dialogue depuis la raison naturelle sont devenues I'histoire d'une infidélité, puisque les pères conciliaires avaient adopté une perspective nettement théologique pour établir ce dialogue avec le monde. L'argument théologique doit être proposé comme partie de la raison publique puisque, même si sa rationalité est transcendante, elle est tout de même communicable et intelligible par $d^{\prime}$ autres interlocuteurs.

L'auteur soupçonne que «l'échec» du dialogue sécularisé peut être dû à l'autocensure du discours religieux dans le domaine du public. Dans la deuxième partie l'auteur souligne la nécessité d'un jugement moral -et il critique son absence dans le discours public et dans l'éthique théologique-, jugement nécessaire pour pouvoir humaniser le monde.

C'est seulement à travers le discernement éthique ouvert par le discours théologique sur le monde que nous pourrons donner un 
reason of the meaning of our hope, what raises the need to rehabilitate the value and the status of that ethical judgment.

Key-words: Anthropology, dialogue, discernment, ethical judgement, theological rationality, secular reason, social status of the Church. sens à notre espérance, ce qui impose la nécessité de restituer la valeur et le statut de ce jugement éthique.

Mots clé: Anthropologie, dialogue, discernement, jugement éthique, rationalité théologique, raison séculaire, statut social de l'Église.

\section{Introducción}

Cuando acepté redactar este articulo pensé que me resultaría sencillo exponer la antropología conciliar ${ }^{2}$. Me equivocaba. La ya extensa bibliografía dedicada a Gaudium et spes no para de expandirse, y más aún ahora con el aniversario de su publicación, como puede comprobarse en la bibliografía al final de este artículo. Cuando uno ahonda un poco en lo que se ha escrito en francés, en italiano, en español y en inglés sobre el texto conciliar, se da cuenta de que la cantidad de estudios es enorme. Ha sido una labor larga, que no he concluido, dejando sin revisar textos quizás importantes por falta de tiempo. Sin embargo, la revisión bibliográfica fue suficiente para sugerir una topología de las interpretaciones del texto conciliar y proponer aquí una reapropiación contemporánea del texto.

¿Cómo abordar un texto como Gaudium et spes de manera renovada? ¿Cómo recobrar la ingenuidad primera que nos permita leer un texto sin que se introduzcan por todos los intersticios los comentarios y los análisis de tantos teólogos eminentes que ya lo hicieron? Era necesario tomar algunas opciones.

La primera opción consistió en no desglosar ni rehacer la historia del proceso de redacción de Gaudium et spes. Este trabajo ya ha sido hecho de manera congruente en la literatura existente ${ }^{3}$. Es un acercamiento útil, que permite identificar los puntos discutidos, las opciones tomadas por los padres conciliares, así como las luchas y las formulaciones que finalmente lograron el consenso. Frases, expresiones y esquemas enteros aparecieron, desaparecieron y reaparecieron antes de que

\footnotetext{
2 Este artículo trae origen en la conferencia del autor en el segundo Simposio de Pensamiento social cristiano (Barcelona 1-3 de julio de 2015) sobre "La Iglesia en el mundo: la autonomía de la realidad a la luz de la fe, en el cincuentenario de Gaudium et spes . 1965-2015"; cfr. J. SOls LuCIA y M. López Casquete de Prado, RFS 70 (2015) 395-399.

3 Para la historia de la redacción del texto de Gaudium et spes, cfr. TuRBANtI, 2000; DelhaYe, 1967; Heúín, 1985.
} 
fuese votada finalmente la constitución pastoral. Pero también hay que reconocer que esta génesis compleja del texto ha fijado su interpretación sobre los conflictos de la época conciliar (cfr. Congar - Peuchmaurd, 1967, T. 2.). Teológicamente, la interpretación de los primeros comentaristas de la Gaudium et spes refleja esta génesis, identificando el significado del texto con los pasajes que fueron más controvertidos durante el concilio y dejando los párrafos más consensuales de lado.

La segunda opción de lectura que adopté consistió en tomar una perspectiva radicalmente fenomenológica y hermenéutica. Siguiendo a Paul Ricoeur (cfr. Ricoeur, 1986), considero aquí el texto en su autonomía, es decir, desvinculado de las intenciones y pasiones que animaron a los padres conciliares, y lo hago para interesarme por el texto mismo -tal cual existe como texto final- así como por los procesos de reinterpretación del texto a partir del contexto de sus lectores. Propongo a continuación una historia de las recepciones de Gaudium et spes para luego proponer -a raíz de un estudio estructural de los tres primeros capítulos de esta constitución pastoral-mi propia lectura del texto ${ }^{4}$. Espero, así, hacer que del texto mismo surja la perspectiva que el concilio tomó con respecto a la antropología.

Lo primero que hay que afirmar es que nuestro contexto histórico es muy distinto al de Gaudium et spes, y que se trata de un cambio dramático y crucial para la interpretación del texto conciliar. Efectivamente, la constitución pastoral emprende un diálogo abierto con el mundo contemporáneo, esto es, con el mundo de entonces, el de hace cincuenta años, un mundo que ha cambiado de manera importante. Sociológicamente, tecnológicamente y económicamente nuestros pueblos y nuestras naciones difieren de manera importante de lo que eran hace medio siglo. También la Iglesia ha cambiado: derrumbe en Europa, crecimiento en África y Asia, receso en las Américas. Se trata de un cambio que se viene dando desde hace varias décadas en lo sociológico y en lo geográfico, y que el Papa Francisco quiere reflejar ahora también en la alta jerarquía de la Iglesia.

De manera crucial, el estatus social de la palabra de la Iglesia ha cambiado para ser hoy la de un grupo particular, frecuentemente minoritario en sociedades secularizadas, o en vía de rápida secularización ${ }^{5}$. En Europa, en Estados Unidos,

${ }^{4}$ Debo mucho a BORDEYNE, 2004.

${ }^{5}$ Tal como propone Charles Taylor, existen varias formas de secularidad así como diferentes procesos de secularización según los países. Sin embargo, en conjunto propone entender el contexto postmoderno como aquel en el que la creencia religiosa es la excepción, y la ausencia de fe, la nueva norma social. Dicho en clave filosófica: el postulado cultural interno a la secularidad afirma -en clave hegeliana- la superación del cristianismo por avance del espíritu de la historia. Pero lo que era todavía imaginación 
en América Latina, la Iglesia ya no es un interlocutor mayor, sino solo eventual, del diálogo social. Es la representante de una minoría cuyas opiniones morales o antropológicas son consideradas obsoletas por la mayoría de la sociedad; es una voz que expresa una preferencia de tipo privado, pero ciertamente no es una voz con autoridad moral. El postulado positivista de una superación del cristianismo por el avance del espíritu tecnocientífico parece, de alguna manera, ser hoy imperante en nuestra sociedad.

Ahora bien, no solo ha cambiado el estatus social de la palabra de la lglesia, sino que la noción misma de diálogo social ha sido cuestionada. Dialogan las personas, no las sociedades ni las culturas, mucho menos las religiones. Quien emprende el diálogo será siempre un hemiciclo reducido de personas representativas, pero ¿̇cómo se traducen y sobre todo se transmiten los frutos de este diálogo a los sistemas sociales, culturales o religiosos que representan?: este punto no se ha verificado. Aún más, la experiencia demuestra la inocuidad del diálogo sobre sistemas sociales complejos ${ }^{6}$. Siguiendo a Michel Foucault en su descripción de la relación entre poder y verdad, parece que la palabra dominante se impone como «verdad factual» por medio de instituciones complejas, hoy en día siempre más dominadas por una racionalidad técnico-mercantil (biopoder). Dicho de otro modo, son los juegos de poder los que determinan cuál es la palabra autorizada e imponen un ethos social que plasma su propia racionalidad. Según Foucault, quien domina la palabra que tiene autoridad impone el nomos («norma») que conlleva su verdad (Gordon, 1980: 108ss).

La dominación y dirección de las instituciones claves de esta autorización de la palabra son, entre otros, el Estado, el poder judicial, las universidades, los medios de comunicación de masas y la industria del entretenimiento. En estos cinco ámbitos se hace patente también un alto grado de secularización.

y deseo para Augusto Comte ha dejado de ser una opción filosófica para llegar a ser una realidad masificada. La increencia es la nueva norma de existencia posmoderna. Por lo tanto, en una sociedad secularizada, creer significa creer desde la ausencia de fe, es decir, desde su negación constante en todos los ámbitos de la vida pública. Esta inversión rápida y masiva coincide con la marginación de la fe en el ámbito público, así como su reducción a la expresión de una preferencia privada. (Cfr. TAYLOR, 2007; GUARDINI, 1950).

' Tomen como ejemplo el supuesto debate público que hubo en Francia sobre el «mariage pour tous» (el «matrimonio para todos»). No hubo ni debate ni diálogo. La decisión fue política, tomada por un gobierno que, teniendo mayoría en el parlamento, sabía que podía hacer pasar la ley fuera cual fuese el parecer de la oposición. En la sesión parlamentaria se hizo evidente la carencia de diálogo en esta decisión tomada ya previamente. No había forma de alterar la voluntad del gobierno, que era la de imponer esta reforma. Las protestas masivas en las calles de París no sirvieron para nada. 
De ahí que el proyecto que enuncia y sostiene Gaudium et spes como su objetivo - generar un diálogo con el mundo- parezca hoy sumamente ingenuo. Pero es precisamente en este contexto actual donde el texto de Gaudium et spes cobra nuevo vigor, una nueva fuerza nunca imaginada, probablemente ni siquiera por los padres conciliares mismos. ${ }^{7}$

En este estudio retomaré el texto de Gaudium et spes, primero viendo la validez del tema antropológico como base de un diálogo entre la Iglesia y el mundo actual. Luego, en la segunda parte, propondré una lectura estructural de los tres primeros capítulos de Gaudium et spes, que ponen de relieve la peculiaridad del tratamiento del tema antropológico en el texto. Finalmente, terminaré concluyendo que la antropología del concilio no es solo teológica, sino que también tiene en la fe cristiana su coherencia argumentativa. Destacaré esto con dos elementos claves de la herencia conciliar: la noción dinámica de dignidad humana y el discernimiento de los signos de los tiempos.

\section{La antropología como base del diálogo entre la Iglesia y el mundo actual}

¿Por qué elegir la antropología para un diálogo con el mundo? Es necesario aquí recobrar la intención y el propósito del concilio tal y como lo formula el propio concilio al elegir a la persona humana como tema central de este documento (Tucci, 1967a). De ahí que se deba leer nuevamente el proemio y el prólogo del texto. Cito el primer párrafo de Gaudium et spes:

Los gozos y las esperanzas, las tristezas y las angustias de los hombres de nuestro tiempo son a la vez los gozos y las esperanzas, las tristezas y las angustias de los discípulos de Cristo (...) No hay nada verdaderamente humano que no encuentre eco en su corazón. (\$1)

Primer punto: El concilio se interesa por la antropología, pero no en un nivel teórico, sino desde una perspectiva existencial. Los padres conciliares $-y$ con ellos la Iglesia- se identifican con las esperanzas y los gozos, las tristezas y las angustias de los hombres. Nada de lo que es verdaderamente humano es extraño al cristianismo. Por lo tanto, si el concilio elige a la persona -a la antropología- como el tema de su exposición es porque se siente verdadera e íntimamente solidario con el género humano y su historia (cfr. Bordeyne, 2004: 147-166). La historia de los hombres es también la historia de la Iglesia. Esta íntima solidaridad es la que

7 Debo esta idea a KREUTZER, 2006. 
justifica la necesidad con la cual el tema antropológico se impone a los padres conciliares. La Iglesia está encarnada en la historia humana.

Segundo punto: Si el concilio se interesa por la historia de los hombres es porque la salvación en Cristo no está dirigida a individuos aislados, sino a la humanidad entera. No somos salvados solos, sino juntos. La Iglesia es pueblo de Cristo, cuerpo de Cristo, familia humana escatológicamente unificada en la persona de Cristo por medio del Espíritu Santo. Esta es la segunda razón por la cual el concilio toma la antropología como objeto de diálogo con el mundo: porque la salvación misma no va dirigida a individuos, sino a la comunidad, al hombre en tanto que sujeto que constituye una comunidad. La Iglesia no puede dejar de emprender un diálogo con el mundo, con la comunidad humana. Lo requiere la salvación misma.

Nótese, sin embargo, que ambos puntos son profundamente teológicos. Si el diálogo con el mundo toma la antropología como objeto de discusión, esto no se debe a la búsqueda de un tema neutro de discusión, afín a una razón secularizada, sino a motivos teológicos.

Es la persona del hombre la que hay que salvar; es la sociedad humana la que hay que renovar. Es, por consiguiente, el hombre, pero el hombre entero, integral, quien será objeto de este texto. (\$3)

Tercer punto: ¿əPor qué emprende la Iglesia este diálogo sobre el hombre? Porque lo entiende como un servicio que ella brinda al mundo a la luz de la Revelación. La Iglesia comparte y acompaña a los pueblos en sus tribulaciones y en sus interrogantes apremiantes, ya que estas son también las suyas.

Resulta interesante la lista que el concilio presenta de los interrogantes que plantean los desafíos de mediados del siglo xx. Aquí se percata uno del objetivo del diálogo que busca la lglesia con el mundo. Dije anteriormente que era un diálogo existencial, un diálogo directamente ligado a la salvación y a la solidaridad y, por lo tanto, concreto, determinado por una situación y un tiempo particulares. En un mundo, el del tiempo del concilio, que todavía se reconstruye después de las dos guerras mundiales, marcado por la guerra fría y testigo de las guerras de independencia de las antiguas colonias, cuatro preguntas parecen apremiantes (Bordeyne, 2004: 11-15). El género humano se interroga con angustia sobre:

- la evolución actual del mundo;

- el lugar y la función del hombre en el universo;

- el sentido de los esfuerzos individuales y colectivos;

- el destino último de las cosas y de la humanidad. 
¿Quién se hace estas preguntas? El género humano, el hombre. ¿Cuál es el objeto de discernimiento? El mundo, el Universo, las cosas, la humanidad, la acción humana. ¿ Qué se debe determinar? La evolución, el sentido, el destino último. ¿Cuál es el contexto de esas preguntas? Un cambio rápido del mundo, marcado por incertidumbres y peligros, esto es, una situación en la cual la humanidad se encuentra confrontada con la ambigüedad de las fuerzas que trabajan la historia humana y al mismo tiempo llamada a tomar decisiones importantes sobre el futuro de la humanidad.

A esta situación corresponde por lo tanto la necesidad de un discernimiento, es decir, de un juicio que haga surgir el sentido de lo humano en los cambios excepcionales que experimenta la humanidad. En estos cambios, efectivamente, la Iglesia se preocupa de lo que le espera al hombre. Frente a la ambigüedad y la angustia, la Iglesia quiere vislumbrar cómo aquí y ahora -hic et nunc- se despliega la vocación integral del ser humano.

Esta necesidad de un discernimiento de los signos de los tiempos se impone, por tanto, no como una expresión de orgullo de la Iglesia ("iAquí vengo a explicarles a ustedes el sentido del mundo!»), sino como expresión de su solidaridad, tanto en las incertidumbres como en las esperanzas de la humanidad. No es que la Iglesia tenga «información privilegiada» acerca del devenir de la humanidad: simplemente, a la luz de la Revelación, quiere ayudar a discernir en la historia el sentido último de la vocación humana.

Enfatizo aquí tanto la necesidad del discernimiento como la forma que adopta 8 . Discernir es aplicar un juicio, pero un juicio que -a diferencia de los juicios legales- no quiere buscar la verdad sobre un hecho pasado, sino abrir un futuro posible. El ejercicio de discernimiento al que apela Iglesia, y que pone en práctica en Gaudium et spes, no busca condenar herejías, ni separar de manera drástica un error de una verdad, sino alumbrar el futuro de la humanidad para abrir un camino posible, un camino verdaderamente humano.

Esto tiene su importancia: permite rechazar varias interpretaciones de la antropología de Gaudium et spes poco coherentes con la intención del concilio. Gaudium et spes no pretende ser un texto dogmático', sino un texto pastoral de índole existencial.

${ }^{8}$ Este aspecto fue centro de atención en un coloquio en Lovaina (Flandes) en 2004, posteriormente publicado en VerSTRAETEN (2007).

9 Una tentación a la cual no escapan GertLer, 1986, ni Russo, 1983. 
No se trata de una exposición completa de una doctrina sobre el hombre, sino de un discurso que tiene su fundamento en la tradición apostólica y que pretende responder a los signos de los tiempos. El carácter incompleto de la antropología conciliar no es, por tanto, problemático.

Así, existen varios comentaristas (cfr. Ratzinger, 1969; Xavier, 2010; De Lubac, 1968) que critican al concilio por el hecho de no haber incluido uno $u$ otro elemento considerado como 'imprescindible' de una antropología moderna (psicoanálisis, dimensión sistémica, etc.). No es que Gaudium et spes sea una constitución pastoral incompleta, sino que su propósito nunca fue antropológico ${ }^{10}$. Este texto nunca fue pensado como un tratado antropológico. Se trata de un documento del magisterio pastoral, que, como cualquier otro, es incompleto y remite, para su interpretación, al conjunto de la tradición apostólica.

Asimismo, se pueden rechazar las lecturas críticas de los comentaristas que, al igual que el joven Ratzinger (futuro papa Benedicto XVI), aducen que la antropología de Gaudium et spes es semipelagiana, su cristología, incompleta (Ratzinger, 1969), y su comprensión trinitaria, interesante pero ambigua. Estas críticas no son pertinentes, porque no tienen en cuenta que el propósito del concilio en Gaudium et spes no es dar una antropología completa, sino expresar, a la luz de las cuatro preguntas formuladas más arriba, los puntos antropológicos relevantes que permitan aportar respuestas. El texto no es dogmático, sino pastoral; y no condena herejías, sino que nos orienta hacia el futuro.

\section{Lectura estructural de los tres primeros capítulos de Gau- dium et spes}

\section{I. Interpretaciones de Gaudium et spes}

Aquí, al presentar las diversas interpretaciones que se han hecho de Gaudium et spes, tengo que aludir a un aspecto de la génesis del documento como tal. Esa génesis fue larga, compleja y debatida. Se discutieron varios esquemas, que fueron primero rechazados y luego fusionados entre sí por distintos redactores. Básicamente, en la génesis del documento existen dos esquemas principales: uno más conceptual y otro de índole más práctica, dedicado a una serie de problemas

${ }^{10}$ Algo que debo a García Fernández, 2007. 
contemporáneos. Esta dicotomía se refleja en el documento actual con sus dos partes: una primera teórica que abarca lo que es conocido como la antropología conciliar, y la segunda que retoma la forma de las encíclicas sociales y aborda, por tanto, problemas concretos.

Lo más relevante para nuestra investigación se ha de buscar en la primera parte, propiamente antropológica, y más específicamente en los tres primeros capítulos de Gaudium et spes. Hay que advertir, sin embargo, que los padres conciliares insistieron sobre la unidad y continuidad del documento, y que varios elementos de los tres primeros capítulos pueden y deben ser completados con elementos tomados de la segunda parte. Esto es peculiarmente cierto para el capítulo II (la comunidad humana), cuyas dimensiones despliega la segunda parte (matrimonio y familia, cultura, política, economía, comunidad internacional).

La revisión de la bibliografía existente permite identificar la historia de la interpretación de un texto como Gaudium et spes. Propongo a continuación una tipología rápida de las interpretaciones que se han hecho de la antropología de Gaudium et spes. Como cualquier tipología, la clasificación histórica que emprende es reductora y discutible, pero sirve aquí para situar y diferenciar nuestra propia interpretación.

Podemos diferenciar las interpretaciones del concilio en relación a tres periodos históricos:

1) De 1965 a 1975 la literatura acerca de Gaudium et spes todavía se desarrolla en la cercanía inmediata del concilio (cfr. Congar - Peuchmaurd, 1967, T. 3; Herrera Oria, 1968; Ratzinger, 1969). Con frecuencia se trata de comentarios por parte de padres conciliares o de teólogos que participaron en el concilio. Sus interpretaciones están obviamente marcadas por la génesis del texto, llena de ambigüedades y conflictos. Son comentarios o interpretaciones habitualmente muy conscientes de las tensiones presentes en el texto conciliar, y tratan de explicarlas en relación a su génesis. Frecuentemente estos autores aún toman posición sobre contenidos del texto como si el debate no se hubiera acabado y se necesitara clarificar el sentido original de uno u otro párrafo.

2) Una segunda oleada de interpretaciones sucede a partir del $20^{\circ}$ aniversario de la clausura del concilio, esto es, a partir de 1985 (Latourelle, 1988; Gertler, 1986; Karakunnel, 1984; Kaspers, 1986; Russo, 1983; Sartori, 1995; Ladaria, 1988). Aquí el tono es marcadamente diferente: tenemos una serie de teólogos que emprenden el desarrollo del proyecto conciliar, específicamente de la antropología conciliar. Estos autores se dedican a continuar el esfuerzo 
conciliar, despliegan la antropología y la completan en busca de unidad y de coherencia. Para estos autores, el carácter incompleto del texto no resulta problemático, sino que da lugar al desarrollo de una antropología conciliar, lo que da autoridad a cada autor por el hecho de fundamentarse en el concilio. Seré franco: el segundo período resulta insufrible por arrogante cuando lo revisamos treinta años después. Estos autores, sobre la base de la primera oleada de comentarios, no dudaron en presentarse como auténticos intérpretes del concilio: "Gaudium et spes es transparente y claro; aquí os mostramos la antropología que propuso el concilio», solían afirmar. En realidad, se sacaron esa antropología de la manga recurriendo a elementos filosóficos, económicos o políticos completamente ajenos al texto. Lo que más asombro provoca es el hecho de que consideren Gaudium et spes como un texto ingenuo de la lglesia, que solo gracias a ellos adquiere la categoría de ciencia. Desafortunadamente, encontramos esta arrogancia también en algunos de los comentarios de la tercera generación, que vamos a ver a continuación.

3) Se puede identificar una tercera generación de comentaristas o intérpretes del texto de Gaudium et spes, a la cual pertenece nuestro estudio (Kirchhoffer, 2013; Kreutzer, 2006; Tanner, 2005; Turbanti, 2000; Xavier, 2010; Gagliardi, 2009; García Fernández, 2007). Estos autores quieren regresar al texto del concilio porque su contexto ha cambiado lo suficiente como para que el documento aparezca ahora como un texto histórico que requeriría de una reinterpretación y de una reapropiación en circunstancias ahora ya bien diferentes.

Tres períodos, tres proyectos diferentes de recepción del texto conciliar que a su vez dan pie a tres grandes formas de interpretación de Gaudium et spes. Las interpretaciones de la antropología de Gaudium et spes dependen principalmente del punto considerado central en este texto por el autor, es decir del énfasis que este ponga en uno u otro de los aspectos del texto conciliar. Veamos cuáles son esos tres grandes tipos de interpretaciones antropológicas:

1) Cristología. Varios autores vieron en la dimensión cristológica de esta antropología su punto central y específico (Ladaria, 1988; Russo, 1983; Gertler, 1986; Gagliardi, 2009). La antropología de Gaudium et spes se presenta en ellos teocéntrica y cristocéntrica. En primer lugar, estas lecturas de la antropología conciliar son dinámicas, siempre atentas a la forma mediante la cual el hombre encuentra a Dios en el interior de su condición histórica y comunitaria, es decir, a través de su acción hacia los otros. $Y$ en segundo lugar, son lecturas que enfatizan la vocación del hombre. En cuanto creado a imagen y semejanza de 
Dios (imago Dei), el hombre ha de conocer y amar a Dios en la especificidad de las circunstancias históricas que le toca vivir. Se trata de una estructura fundamentalmente cristológica, en la que el hombre nace y se ordena a Dios a través del mundo. Estamos ante un esquema antropológico que ya es clásico en teología, expresado ahora con categorías nuevas. Entre estas sobresalen el énfasis puesto en las relaciones que existen entre el hombre y Dios, la historia y Cristo, la cultura y el Espíritu, haciendo hincapié en puntos de la dogmática cristológica, como pueden ser el Espíritu de Cristo, la encarnación o la doble naturaleza. Abundan las interpretaciones sensibles a las fragilidades dogmáticas del texto.

2) Justa autonomía. Un segundo grupo de interpretaciones gira en torno a las nociones de ateísmo y de justa autonomía de las realidades creadas. Estos autores del posconcilio destacan la alusión al ateísmo del capítulo I (cfr. de Lubac, 1968; Mouroux, 1967). Esto ya no es algo clásico, sino todo lo contrario. El anticlericalismo de la llustración francesa había creado un antagonismo explícito entre la fe cristiana y el ateísmo moderno. La introducción aquí del ateísmo como elemento de una antropología cristiana sorprende, y es para Henri de Lubac un punto sobresaliente de Gaudium et spes. Estos autores defienden que el ateísmo no se reduce a su oposición a la fe cristiana, sino que posibilita una purificación de la antropología promovida por la lglesia. El ateísmo permite una catarsis de las nociones de hombre, de mundo, de cultura e incluso de Iglesia, en cuanto que habla de la cultura del mundo y del hombre. Catarsis, purificación: he aquí las temáticas centrales de esta lectura de la antropología conciliar. En esta perspectiva, la relación del hombre con Dios se concreta en temas clásicos como la relación entre razón y fe, entre lo natural y lo transcendente, entre la ciencia y la teología. El punto central, sin embargo, de estas lecturas de la antropología conciliar será establecer la justa autonomía del mundo creado y del actuar humano. La autonomía no es problemática ni contestada (es un tema ya antiguo en la literatura teológica). El problema es saber dónde ha de fijarse la medida de esta justa autonomía. Al emplear el expresión justa autonomía los padres conciliares recurren al famoso término medio aristotélico, resultante del equilibrio entre dos excesos (exceso de dependencia / exceso de autonomía), pero solo responden teológicamente a la pregunta acerca de cuál es este término medio. ¿¿Dónde está el punto de equilibrio? Un análisis estructural del capítulo I no deja lugar a dudas: el criterio último es cristológico (véase más abajo: esquema I). La autonomía ha sido creada, es decir, ha surgido de una relación anterior, $y$ es en esta donde encuentra tanto su fundamento como su finalidad $y$, por tanto, la razón de su justo equilibrio entre el exceso de dependencia y el exceso de autonomía. 
3) Pastoral de la Iglesia. Finalmente, se puede identificar un tercer gran grupo de interpretaciones de índole eclesiológico-pastoral. Aquí, los autores identifican como punto sobresaliente del texto el papel de los cristianos en el mundo actual $^{11}$. Estas interpretaciones enfatizan temas como los signos de los tiempos, o bien el compromiso de los cristianos en el mundo, o bien la aportación de Iglesia al mundo para promover la dignidad humana y el desarrollo integral de la persona. Aquí, la mayor parte de las temáticas y preguntas relevantes tienen que ver con el carácter existencial de la fe. En estas interpretaciones, la antropología teológica de Gaudium et spes se caracteriza, en primer lugar, por su perspectiva radicalmente existencial; en segundo lugar, por la insistencia en la necesidad del discernimiento moral y teológico; y en tercer lugar, por la necesidad de analizar las realidades del mundo contemporáneo. Según estos autores, este programa antropológico del concilio requiere de una apertura de la teología moral a los conocimientos de las ciencias humanas para permitir el imprescindible discernimiento de los cristianos en su presente histórico.

La impresión que da la lectura de este corpus de interpretaciones es que el texto conciliar apenas es respetado en su coherencia argumentativa propia. Resulta asombroso ver hasta qué punto algunos autores han seleccionado los párrafos que más les interesan para desarrollar un argumento que, por muy sugerente que sea, solo es tangencial al texto conciliar ${ }^{12}$. De modo que las tres interpretaciones que acabamos de ver no pueden ser consideradas como expresión auténtica de la antropología de Gaudium et spes, algo que Bordeyne ya me había señalado como una de las dificultades del proceso de recepción del texto conciliar. Siguiendo su ejemplo, propongo a continuación una lectura estructural de Gaudium et spes, que intenta sencillamente poner de relieve el proceso argumentativo del texto, $y$ por tanto la concatenación de temáticas teológicas que operan los padres conciliares en Gaudium et spes. Las tablas que siguen aquí resultan de este trabajo de honestidad intelectual que debemos al texto y ponen de relieve la estructura teológica de la antropología de Gaudium et spes, mientras que el anexo se puede encontrar el desglose, párrafo por párrafo, del contenido de los tres primeros capítulos del texto.

\footnotetext{
${ }^{11}$ Sin duda, este es el grupo más numeroso. Cfr. TuCCI, 1967; THILS, 1967; SARTORI, 1986; KARAKUnNEL, 1984.

${ }^{12}$ Un punto que resalta particularmente KreUtZer, 2006.
} 


\title{
3.2. Los tres primeros capítulos de Gaudium et spes
}

\section{CUADRO I. Contenido de los capítulos I-III de Gaudium et spes}

\author{
Capítulo I. La dignidad de la persona humana
}

§12-13 La persona humana

- Todo sobre la Tierra ha de ser ordenado al hombre como a su centro y su cima.

- La Revelación divina desvela tanto la fragilidad como la dignidad de la condición humana así como su vocación.

- El hombre creado a la imagen de Dios, capaz de conocerlo y amarlo como su creador, establecido como señor de toda criatura.

- Fue creado hombre y mujer, es decir, en una comunidad, una comunión de personas.

- La relación con el otro es condición de su vida y de su pleno desarrollo.

- El pecado como abuso de la libertad y como rechazo de Dios; el intento de llegar a sus fines fuera de Dios.

- El pecado deja el corazón humano inclinado al mal, disminuido, incapaz de alcanzar su plenitud.

- El pecado rompe el orden que lo ordenaba a su fin último; rompe la armonía del hombre consigo mismo, con los otros, con la creación. El pecado es división interna, lucha contra sí mismo.

- El hombre se descubre alienado, incapaz de vencer en esta lucha interna.

- El Verbo regenera la libertad y la fuerza humana, liberándolo de la esclavitud del pecado.

§ 14-16 La condición humana

- El hombre es cuerpo y alma, pero verdaderamente uno.

- El hombre como microcosmos.

- La corporeidad humana es buena y digna, pero herida por el pecado, necesita purificación.

- En su interioridad, el hombre trasciende el universo de las cosas; el alma inmaterial y espiritual tiende a Dios.

- Por la inteligencia, el hombre supera el universo de las cosas.

- La razón es capaz de alcanzar la realidad inteligible de las cosas.

- Nuestra inteligencia alcanza su perfección en la sabiduría.

- La sabiduría atrae al hombre a su búsqueda del bien y de la verdad.

- La sabiduría humaniza al hombre y al mundo; porvenir de un mundo humano.

- El Espíritu de Dios hace partícipe al hombre de la sabiduría divina (voluntad divina).

- Interioridad y anterioridad de la conciencia.

- La conciencia ordena el bien, manda evitar el mal. Deber de obediencia.

- La dignidad del hombre reside en su obediencia a la conciencia.

- La conciencia como santuario más íntimo donde el hombre solo se encuentra con Dios.

- La solución a los problemas sociales y morales actuales ha de ser buscada en la fidelidad a la conciencia.

- Ignorancia invencible, ignorancia culpable.

§17-18 Significado del actuar humano

- El hombre siempre emprende el bien libremente. Ha de buscar por sí mismo a su creador y amarlo.

- La verdadera libertad es siempre un signo eminente de la imagen de Dios.

- El hombre ha de actuar de manera consciente y libre, según su convicción personal.

- Su dignidad exige que se comporte según la norma de esta libertad.

- La dignidad de la libertad se realiza en la elección del bien y en la consecución de su vocación.

- Dañada por el pecado, la libertad ya no puede ordenarse a Dios de manera efectiva e integral.

- El enigma de la condición humana llega a su cima cuando el hombre se enfrenta a la muerte.

- La muerte no constituye el término último ni el fracaso definitivo de la persona.

- El germen de eternidad presente en el hombre se rebela contra la muerte, aspirando a una vida más allá de esta.

- Dios ha creado al hombre para una vida bienaventurada que supere las miserias del tiempo presente. 
- Mediante su muerte en cruz, Cristo libera el hombre de la muerte, para alcanzar así una comunión eterna en la vida divina inalterable.

- La fe responde a la angustia de la muerte que habita en el corazón humano.

§19-21. Negación de Dios y del sentido de la vida

- El hombre fue creado para vivir en el amor de Dios.

- Muchos rechazan el lazo que une el hombre con Dios y hasta niegan su existencia.

- Diversidad de formas de ateísmo.

- La Iglesia lamenta todas las formas de ateísmo y busca las causas escondidas del rechazo que algunos hacen de Dios.

- La fe en Dios no se opone al reconocimiento de la dignidad humana. La esperanza escatológica no aleja a los creyentes de los dramas del mundo contemporáneo.

\$22. Cumplimiento de la imagen en Cristo

- El misterio del hombre sólo se desvela verdaderamente a la luz del misterio del Verbo encarnado.

- Todos los elementos anteriores (mencionado en este capítulo) encuentran en Cristo su fuente y su cumplimiento.

- Cristo desvela la vocación humana al amor.

- Cristo, hombre perfecto, restaura en el hombre la semejanza divina; eleva la naturaleza humana a una dignidad sin igual.

- Cristo por su encarnación, ha asumido lo cotidiano de la vida humana.

- Cristo, cordero pascual, ha reconciliado al hombre con el Padre, liberándole de la esclavitud del pecado.

- El don del Espíritu de Cristo desvela el sentido nuevo y último de la vida humana, así como desvela a los otros como multitud fraterna.

\section{Capítulo II. La comunidad humana}

\$23 Persona, comunidad y comunión

- Mundo actual: multiplicación de relaciones.

- La multiplicación de las relaciones entre pueblos todavía no conforman un diálogo fraterno.

- El diálogo requiere el respeto recíproco a la plena dignidad espiritual de cada uno.

- Este respeto conforma una comunión de personas.

- La revelación permite tener una inteligencia más aguda de las leyes de la convivencia social.

§24-25 Constitución de la dimensión social del ser humano

- Todos los hombres constituyen una sola familia y han de tratarse como hermanos. Todos surgen de un mismo designo, todos están ordenados a un mismo fin.

- El amor de Dios y del prójimo como plenitud de la ley.

- El hombre llega a su plenitud en la comunión y en la donación de sí mismo.

- Existe une interdependencia y una reciprocidad entre persona y sociedad.

- Las instituciones sociales condicionan el cumplimiento de la plena vocación humana.

- La familia y la pertenencia a comunidades políticas, económicas y culturales son necesarias para el pleno desarrollo humano.

- Las estructuras sociales son ambiguas. Marcadas por el pecado, desvían al hombre del bien. Necesidad de la Gracia.

\$26-27 Normas y finalidades de la vida social

- A la extensión sin precedentes de los lazos sociales corresponde una extensión siempre mayor del bien común.

- El bien común abarca condiciones sociales necesarias al desarrollo integral de la persona y la eminente dignidad de la persona humana y sus derechos y deberes universales e inviolables.

- Un orden social conforme al bien común está ordenado al bien de las personas.

- El desarrollo de esta exigencia de dignidad es conforme al movimiento del Espíritu. Ahora bien, es Él quien suscita esta exigencia incoercible de dignidad.

- Urgencia: El respeto del otro como otro yo; ser el prójimo del otro.

- Oponerse a todo lo que denigre o degrade la vida y la dignidad. 
\$28-29 Procesos sociales del bien común y de la dignidad

- Amor y benevolencia hacia el adversario.

- La verdad y el bien social deben de ser buscados en el diálogo.

- El enemigo debe ser perdonado y amado.

- Igualdad de todos. "Porque todos ellos, dotados de alma racional y creados a imagen de Dios, tienen la misma naturaleza y el mismo origen. Y porque, redimidos por Cristo, disfrutan de la misma vocación y de idéntico destino».

- Son contrarias al designo divino todo tipo de discriminación en cuanto a los derechos fundamentales del hombre, especialmente las discriminaciones estructurales.

- Las instituciones humanas están al servicio de la dignidad humana y de su vocación transcendente.

§30-31 Deconstrucción de la dimensión social del hombre y su remedio en la participación y la responsabilidad

- Una ética individualista socava la dimensión social de la persona, la solidaridad del género humano.

- La solidaridad social constituye uno de los principales deberes del creyente.

- Soy responsable de mí mismo y de los otros.

- Esta responsabilidad exige educar a los jóvenes para que tengan fuerte personalidad.

- Esta responsabilidad es socavada por la miseria así como por la abundancia; se ve debilitada por el olvido estructural de Dios y la negación de la dignidad humana.

- Esta responsabilidad se fortifica cuando el hombre acepta las exigencias de la solidaridad humana y se compromete con el servicio de la comunidad humana.

- La voluntad de participar en la vida social es la clave para renovar las razones de vivir y de esperar.

§32. Cristo Verbo encarnado y bien común escatológico

- Dios salva el hombre constituyéndolo como pueblo.

- El carácter comunitario del hombre alcanza su perfección y llega a su plenitud con la encarnación del Verbo, y de este modo entra en el terreno de las solidaridades humanas.

- Los creyentes tienen que comportarse entre ellos como hermanos.

- La plenitud de la ley es el amor de Dios y del prójimo.

- El don del Espíritu crea entre los creyentes una nueva comunión en su Iglesia.

- La solidaridad tendrá que incrementarse sin cesar hasta su última coronación en Cristo.

\section{Capítulo III. Actividad humana en el universo}

\$33 Actividad humana bajo la luz de la revelación

- Por el trabajo, la ciencia y la técnica se incrementó el dominio del hombre sobre la naturaleza, y por ende es hoy en día capaz de procurarse muchos bienes.

- ¿Cuál es el sentido/valor de la actividad industriosa del hombre? ¿Qué uso hacer de las riquezas? ¿Cuál es la finalidad de los esfuerzos individuales y colectivos?

- La Iglesia, en medio de estos interrogantes, quiere alumbrar con la luz de la revelación el camino de los hombres.

\$34-35. Marco de la actividad humana

- La mejora de las condiciones de vida por la actividad humana es y corresponde al designo divino.

- Toda actividad, aun la más cotidiana, puede prolongar la gesta divina, la realización del plan providencial de Dios en la historia.

- Cuánto más se incrementa el poder del hombre, más se incrementa también el campo de sus responsabilidades personales y comunitarias.

- Los cristianos tienen un deber mayor hacia sus hermanos.

- La actividad humana procede de Dios y se orienta hacia Él.

- El trabajo humano no solo produce riqueza, sino que también permite al hombre superarse y perfeccionarse.

- Lo que el hombre aporta para que haya en el mundo más justicia, más fraternidad y más orden social supera el valor del progreso técnico.

- La promoción humana supera su base material. 
§36. Libertad real dentro del designo divino

- Los contemporáneos temen la religión porque la ven como una amenaza para la autonomía del hombre, de la sociedad y de la ciencia.

- Existe une autonomía perfectamente legítima de las cosas y de los hombres, que corresponde a la racionalidad creada para cada una de ellas.

- Es falso que autonomía signifique que las cosas creadas no dependen de Dios y que su uso pueda hacerse sin referencia alguna a Él.

- La criatura sin su creador se desvanece. El olvido de Dios hace opaca a la criatura.

§37. El pecado, dinámica contraria a la libertad humana

- El incremento de poder y de la tecnología es ambigua; puede servir tanto al bien como al mal, puede estar tanto al servicio de la humanidad como al de su destrucción.

- El mundo conoce una jerarquía de valores turbada; se confunde al bien con el mal.

- El mundo no es todavía el lugar de una única y real fraternidad.

- Este combate no pasará, sino que marcará toda la historia de la humanidad y durará hasta el final.

- El hombre debe estructurarse siempre en torno al bien y no modelarse en función del mundo presente, sino del mundo que le adviene.

- Purificación necesaria de la actividad humana en la muerte/resurrección de Cristo.

- En Cristo, el hombre recibe un incremento de poder y de conocimiento a través de un espíritu de pobreza y de libertad.

- La posesión verdadera del mundo ha de ser como la de "quien no tiene nada y lo posee todo».

§38-39 La esperanza del Reino difundida por el Espíritu como verdadera fuerza de la acción humana

- El Verbo encarnado conforma el fundamento de la fraternidad universal así como la vocación al amor.

- Cristo es constituido Señor por su resurrección; todo poder le es dado; y actúa en el corazón de los hombres con la potencia del Espíritu.

- El Espíritu suscita el deseo del Reino, da testimonio de la tierra que vendrá, alienta el servicio del hombre. Es la esperanza eterna que vive el hombre en la historia.

- El Espíritu hace libres a los hombres para que se proyecten hacia el futuro. Tal es la esperanza cristiana.

- Ignoramos cuál será el momento del fin. Pero sí tenemos una certeza: Dios nos prepara una tierra nueva y un cielo nuevo.

- En la tierra nueva y el cielo nuevo no habrá ambigüedad, ni fragilidad, ni corrupción; solo habrá caridad, justicia, paz y felicidad eternas.

- El valor de la dignidad, de la libertad y de la comunidad purificada y transfigurada participa de la tierra nueva y de un cielo nuevo.

\subsection{Estructura del texto}

¿Por qué privilegiar un análisis estructural del texto? Se sabe que la génesis del texto conciliar fue complejo. Gaudium et spes es el resultado de varios ciclos de redacción / enmiendas / correcciones / nueva redacción a lo largo del concilio. En cada revisión del texto realizada por el pleno del concilio hubo propuestas de cambio de estructura, de temas, de párrafos, de frases o palabras. Tal proceso de redacción implica que los padres conciliares dieron finalmente su aprobación al menos a dos elementos del texto actual: a su estructura y a su contenido. De ahí que un análisis estructural sea importante, porque la forma del texto fue muy trabajada, especialmente en lo que a los tres primeros capítulos de Gaudium et spes se refiere. 


\section{CUADRO 2. Estructura del capítulo primero de Gaudium et spes}

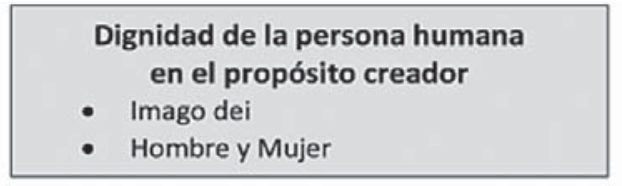

Historicidad de la persona y de la comunidad humana: el pecado, la salvación, el llamado, la esperanza.

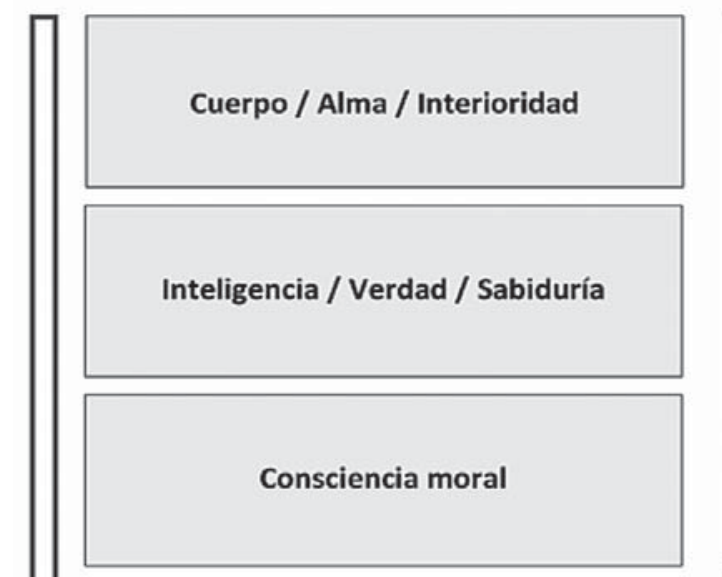

La libertad humana
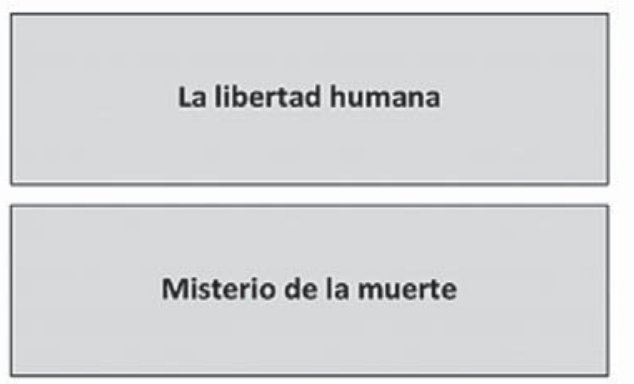

$\int$
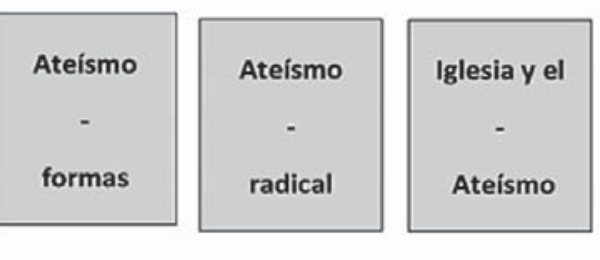

\section{Cristo como hombre nuevo}

- Plenitud de la imagen

- Plenitud del significado

- Plenitud del amor
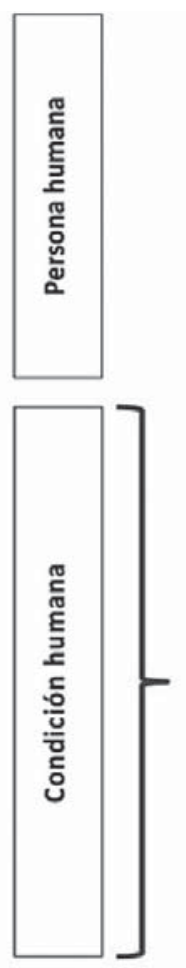

임
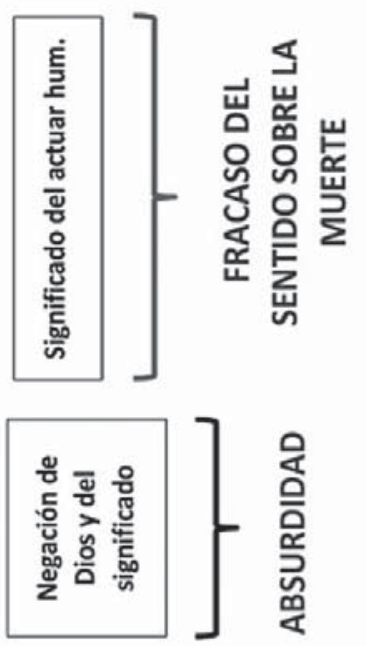

웅

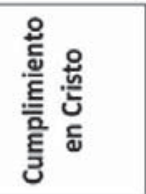

Designo divino sobre el hombre Vocación del hombre<smiles>C1=CCC1</smiles>

I

Despliegue de la imagen como despliegue dinámico del significado verdadero / bueno del hombre...

$$
\begin{aligned}
& \text { I } \\
& \text { I } \\
& \text { I } \\
& \text { I } \\
& \text { I } \\
& \text { I } \\
& \text { I } \\
& \text { I } \\
& \text { I } \\
& \text { I } \\
& \text { I } \\
& \text { I } \\
& \text { I } \\
& \text { I } \\
& \text { I }
\end{aligned}
$$

Cap. I. Dignidad de la persona humana en su vocación trascendente 


\section{CUADRO 3. Estructura del capítulo segundo de Gaudium et spes}

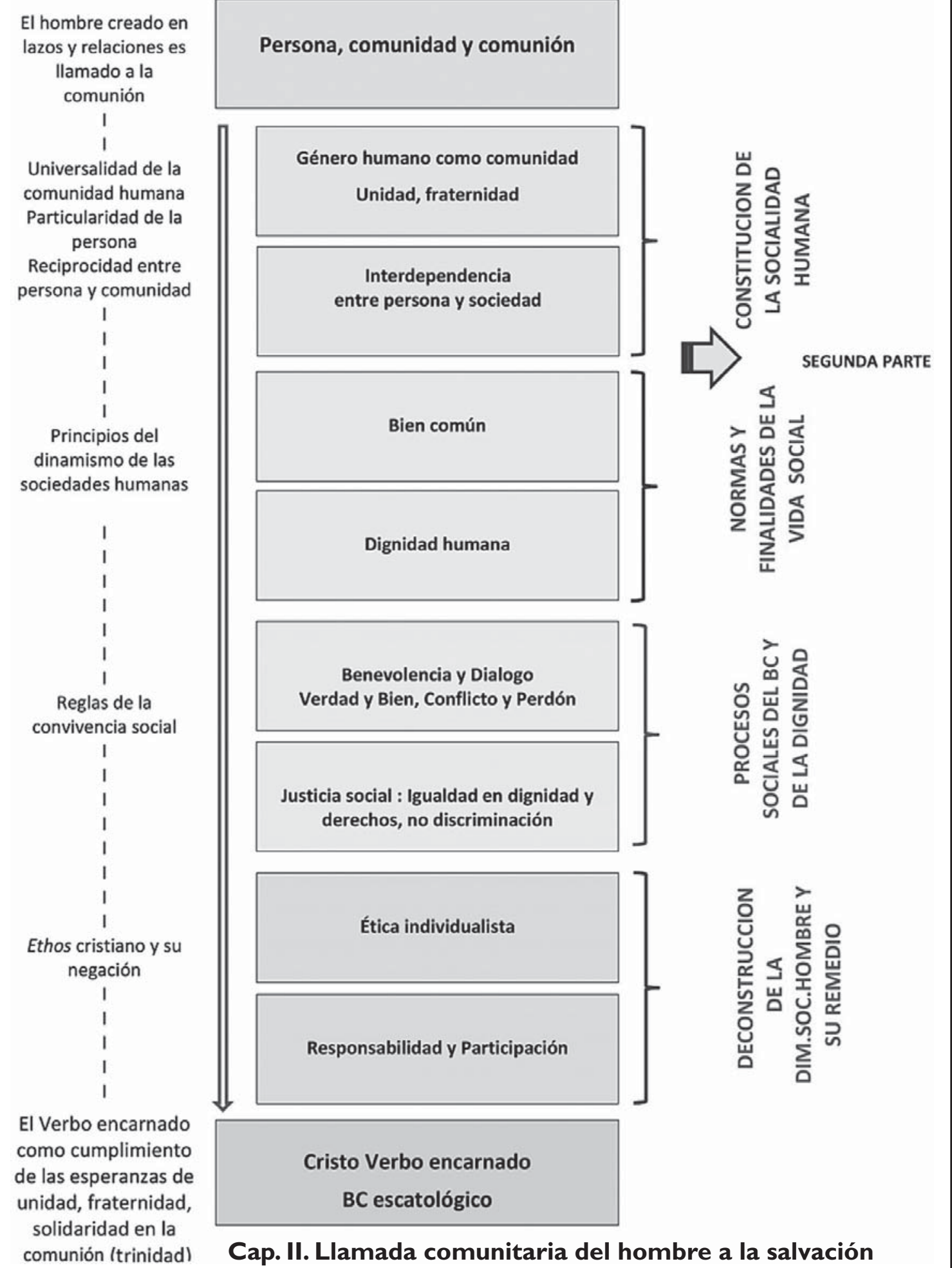




\section{CUADRO 4. Estructura del capítulo tercero de Gaudium et spes}

Finalidad y sentido de la actividad humana Valor y uso de los bienes producidos

1
1
1
1
1
1

La actividad humana procede del hombre, y se ordena al hombre; pero el hombre mismo es ordenado a Dios

$$
\begin{aligned}
& 1 \\
& 1
\end{aligned}
$$$$
\text { I }
$$

Entre la justa autonomía de las cosas, la libre creatividad de la actividad humana ha de desplegarse, pero solo cobra sentido si usa de las cosas conformemente al designo divino

Ruptura del cuadro normativo de la acción

$$
\text { I }
$$

$$
\text { I }
$$

$$
\text { I }
$$

Acción humana y acción del Padre, unidos en la persona de Cristo, en la dunamis del Espirito La esperanza cristiana del Reino de Dios
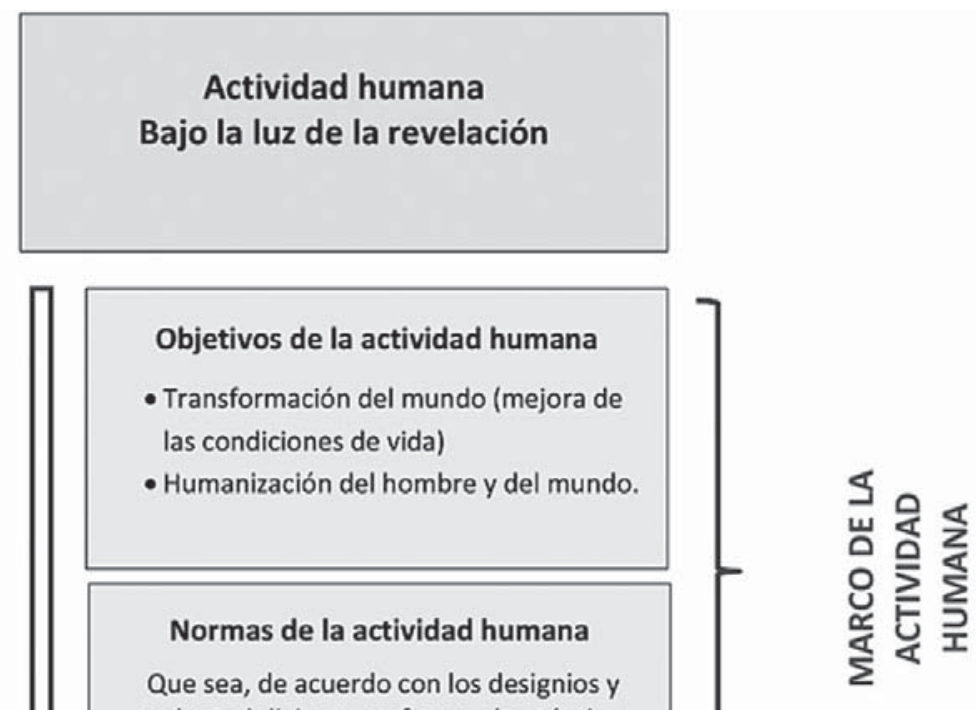

voluntad divinos, conforme al auténtico bien del género humano y permita al hombre, realizar integramente su plena vocación.
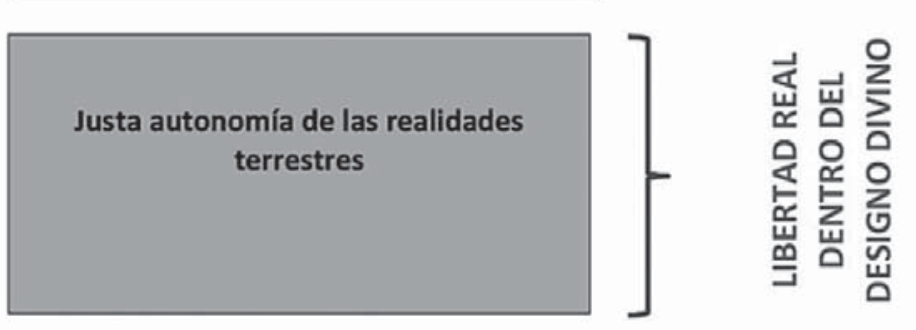

Deformación de la actividad humana por el pecado

- Pérdida del sentido

- Desvío de la actividad humana

- Alienación y destrucción del hombre

Perfección de la actividad humana en el misterio pascual

Tierra nueva y cielo nuevo

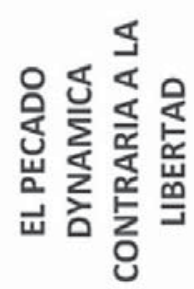

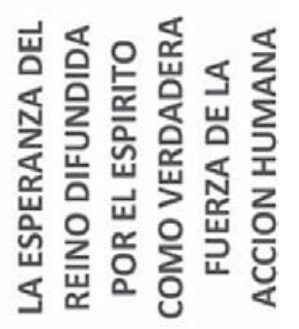

Cap. III. La esperanza que guía y anima la actividad humana 


\section{I.2. Comentarios acerca de la estructura del texto}

Los esquemas que he presentado hablan por sí solos y no requieren de una paráfrasis en lo que a su temática se refiere. Los comentarios que voy a exponer a continuación se refieren a la dinámica del argumento y, por ende, de la antropología teológica que propone el concilio en este texto.

1) Los esquemas anteriores demuestran que existe en el conjunto de los tres primeros capítulos de Gaudium et spes un único esquema de redacción, que presenta una progresión dinámica hacia el último párrafo, explícitamente teológico y cristológico (eschaton). A su vez, cada capítulo empieza con un primer párrafo, solo implícitamente teológico, en el que las nociones de Espíritu, de Cristo o de Dios aparecen con leves matices y con afirmaciones prototeológicas, esto es, que siendo teológicas no llegan a explicitar su dimensión teológica. Por lo tanto, cada capítulo se construye sobre la progresión que va del orden de la creación al de la salvación (Xavier, 2010). Esta progresión se realiza por medio de la encarnación del Verbo, en cuanto este asume y redime la humanidad. Parte del genio de este esquema radica precisamente en el hecho de que la encarnación se desvela desde su polo humano, desde la condición humana - don y capacidad natural; valores y norma; límites, ambigüedades y condición caída- en cuanto asumida por Cristo, tal y como lo desvela el último párrafo. Esta coherencia estructural de los tres primeros capítulos constituye definitivamente el mayor cuadro interpretativo de la antropología conciliar: un cuadro teológico dinámico, que muestra la transfiguración de la condición humana en Dios por medio de Cristo y del Espíritu (Kasper, 1986).

2) Otro elemento recurrente en la estructura de estos tres primeros capítulos son los bloques de párrafos centrales que desglosan elementos de la condición humana, de su vocación histórica y trascendente, para invariablemente hacer notar la ambigüedad de esta condición marcada por el pecado. Si hay una peculiaridad antropológica en Gaudium et spes, esta sea quizás la más destacable. El hombre es presentado como un ser frágil, cuyas capacidades fracasan debido a su falibilidad, azotado por la tensión de la esperanza. Bordeyne muestra de manera convincente en su estudio la importancia de esta aproximación a la condición del hombre a partir de sus capacidades y de su fragilidad (Bordeyne, 2004: 171ss).

3) Es una constante de estos tres capítulos el hecho de que la ambigüedad de la condición humana lleve a un punto donde confluyen tanto la vocación histórica del hombre como su vocación trascendente. La condición histórica humana-en su 
dimensión trágica- se abre sobre la oferta en Dios de salvación. Este esquema, repetido en cada uno de estos tres primeros capítulos, no tiene como propósito justificar la fe. El concilio no propone aquí una simple apologética de la fe, sino una visión cristiana que asume plenamente la fragilidad de la condición humana. No solo no niega la realidad de esta ambigüedad propia de la condición humana, sino que también da razón de la esperanza que habita al ser humano, pero no lo hace basándose en una fe solo humanista, sin trascendencia, sino en la fe en la acción de Dios en el hombre y en medio de los hombres. En el primer capítulo, los tres bloques «Libertad humana», "Misterio de la muerte» y "Ateísmo» forman una tríada. La libertad humana misma, de los demás y del mundo -libertad entendida como capacidad para auto-realizarse, para dar sentido a la propia vida- fracasa ante el misterio de la muerte que des-hace al hombre y que parece querer burlarse de los significados que este ha podido dar de sí, de los demás y del mundo. Así, el concilio presenta el ateísmo no tanto como catarsis de la fe, sino como opción que se acomoda a la absurdidad de la libertad humana y acepta la falacia de la esperanza humana. El sentido del ateísmo se entiende en el interior de lo absurdo de la existencia humana. En este punto precisamente difiere la experiencia cristiana, que reconoce tanto la validez de la libertad humana como su falacia acerca del horizonte histórico de la muerte. En el último bloque, el cristológico, el texto conciliar afirma que en el hombre tanto sentido tiene la libertad como la esperanza. El último párrafo, acerca de Cristo, verdadero hombre y verdadero Dios, muestra la solución a los dos temas que atraviesan la condición humana: 1 / la angustia de una libertad confrontada a la muerte, y $2 /$ la esperanza de una libertad que no es vacua. La antropología de Gaudium et spes se construye, por tanto, sobre la paradoja humana, para mostrar la unión fecunda de estos dos temas en la persona de Cristo: verdadero hombre y verdadero Dios.

4) Esta repetición en cada capítulo de la misma estructura proporciona una dinámica narrativa idéntica en todos los capítulos, sin dejar de tener en cada caso un énfasis diferente. En el conjunto de los tres capítulos se observa una progresión no lineal en la antropología, es decir, una progresión que agrega sucesivamente nuevas temáticas a una narrativa coherente. Solo el conjunto de estos tres capítulos proporciona la respuesta que Gaudium et spes da a las esperanzas y alegrías, las inquietudes y las angustias que atraviesan nuestra condición humana. Si se puede hablar de una antropología conciliar, esta se construye sobre cuatro dinámicas fundamentales:

a) de la ambigüedad de la existencia humana al sentido y la claridad

b) de la angustia a la confianza y la esperanza renovadas 
c) de la incertidumbre a la acción

d) de la potencialidad a la realización plena

Cada una de ellas constituye más una dinámica que en eje temático, una dinámica de transfiguración de la condición humana. Es a lo largo de estas dinámicas como se construye la antropología del concilio.

Ahora bien, el siguiente cuadro muestra de manera sencilla la progresión propuesta en cada capítulo, tomando exclusivamente su principio y su fin, es decir, el punto de partida y el punto de llegada de la dinámica que se propone recorrer el capítulo. Se ve entonces claramente que el conjunto se puede leer tanto vertical como horizontalmente hasta llegar a la conclusión: el Espíritu de Cristo anima la historia humana.

\section{CUADRO 5. Visión sinóptica de la dinámica de los tres primeros capítulos de Gaudium et spes}

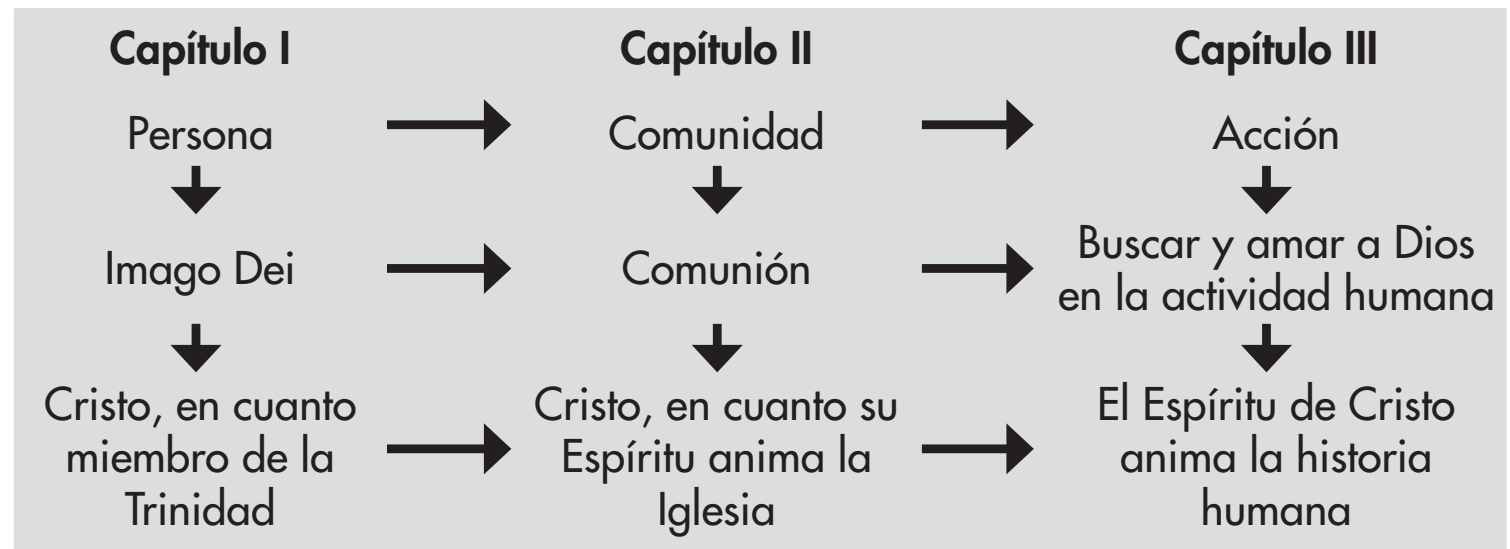

5) En conjunto. El análisis completo de la estructura y del argumento de estos tres capítulos permite resaltar que la antropología de Gaudium et spes no está centrada ni en la cristología ni en la pregunta acerca de la autonomía de las realidades creadas, ni tampoco en el discernimiento del signo de los tiempos, sino en la responsabilidad humana frente a su vocación histórica y trascendente, en una ética teológica de la responsabilidad humana frente a una vocación histórica y trascendente (cfr. BORDEYNE, 2004). El objeto de esta responsabilidad es la realización de la «plena dignidad espiritual del hombre» (\$23).

Quizás sea necesario insistir en la idea de que Gaudium et spes no propone una ética de virtudes ni tampoco una ética de la opción fundamental. Es los que po- 
dríamos denominar una ética de la transfiguración del hombre, una transfiguración tanto de sus capacidades como de sus fragilidades, de sus esperanzas como de sus angustias, de sus fuerzas como de sus fracasos. El hombre, orientado a Dios por medio de Cristo y de su Espíritu, se vuelve libre y responsable en la historia: una libertad liberada para la libertad.

\section{Conclusión}

A modo de conclusión, quiero destacar dos puntos particulares que resultan de esta reapropiación del texto de Gaudium et spes:

1) El primero es el fracaso del propósito de diálogo con el mundo con el que empecé. Me pregunto si el fracaso del diálogo con el mundo que ha intentado la Iglesia no está ligado precisamente a un tipo de infidelidad al concilio, más que al texto mismo de Gaudium et spes. Efectivamente, el tono y el argumento de todo el documento conciliar es explícitamente teológico. Su coherencia es abiertamente teológica y no intenta en ningún momento entablar un diálogo bajo capa de razón secularizada. Los padres conciliares tomaron esta perspectiva en contra de la opinión de varios expertos, que no pensaban que se pudiese entablar un diálogo 'con el mundo' sobre la base de argumentos teológicos. Solo un discurso fundado en la razón -una razón natural, en el discurso de los expertos- permite salir al encuentro del otro, tanto del creyente como del no creyente. Tal como he mostrado, los padres conciliares no optaron por este modelo. Aquí tenemos un texto que es teológico y que es propuesto como modelo de diálogo con el mundo. Visiblemente el concilio consideró que, para hacer frente a la secularidad del mundo, el mejor elemento no era reducir la razón a su dimensión secular, sino mantener que un argumento teológico pertenece al ámbito de la razón, incluso de la razón pública. Su racionalidad, su coherencia racional, si bien transcendente, no deja de ser comunicable e inteligible, aun cuando no se comparta la fe que se está expresando. En este sentido, la recepción del concilio fue poco fiel a lo propuesto en Gaudium et spes. Y quizás el fracaso de un diálogo con la sociedad sea precisamente debido, al menos en parte, a esta autocensura del discurso religioso en el terreno de lo público. Al prescindir de su coherencia teológica, el discurso de la Iglesia pierde su especificidad, se vuelve vago y banal, afirma lo ya aceptado por todos, lo que responde a un consenso general, pierde hasta su propia razón, imprescindible para el diálogo con el otro. Si no se dice nada en particular y todo en general, y además se repiten obviedades consensuadas, entonces nadie entiende la 
razón de dialogar. Quizás convendría revisar el discurso de la Iglesia de los últimos cincuenta años y preguntarse si ha sido fiel al espíritu del concilio.

2) El segundo elemento que quiero destacar vierte sobre los signos de los tiempos. Si se busca en cualquier manual moderno de teología moral, probablemente no se encuentre ni un solo capítulo sobre el juicio moral. La desaparición de la exposición del sano juicio ético en los tratados de ética teológica es un 'signo de los tiempos' de la teología moral. ¡Parece que el cristiano básico puede prescindir en esta época feliz de todo tipo de juicio moral, siendo suficiente algún tipo de opción fundamental básica! ¿̇lncreíble ingenuidad o cobarde capitulación? Hannah Arendt ya lo lamentaba en sus reflexiones sobre el juicio a Adolf Eichmann y veía en él una de las causas de la banalidad del mal (Arendt, 1963). No puedo aquí indagar las razones complejas de esta desaparición del juicio ético del discurso público o de la ética teológica. Pero conste aquí, al menos, que Gaudium et spes sitúa el discernimiento en el centro de su discurso, considerándolo como una de las tareas que incumbe a la responsabilidad del hombre. El juicio responde a la ambigüedad y complejidad de las situaciones concretas que vivimos, $y$ trata de ofrecer la luz de la Revelación a fin de discernir el significado, el valor y las prioridades que nos permitan vivir y esperar. Se trata de un juicio urgente y necesario para humanizar al hombre y al mundo. Si no se disciernen los signos de los tiempos, no vamos a poder encaminar al mundo y al hombre hacia su plenitud en Cristo (Verstraeten, 2007). El último párrafo del tercer capítulo de Gaudium et spes, que aborda el tema de la acción, afirma que solo mediante el discernimiento podremos dar razón del sentido de nuestra vida y de nuestra esperanza. Si no juzgamos, no seremos capaces de explicar por qué vivimos y por qué esperamos. Estamos, por tanto, ante la necesidad de rehabilitar un cierto tipo de juicio, pero no un juicio de tipo legal, ni siquiera aquel propio de la moral casuística, sino aquel juicio que, en medio de la ambigüedad del mundo, nos abra las puertas de un futuro posible (Alfaro, 1988). 


\section{Bibliografía}

\section{I. Obras sobre la antropología de Gaudium et spes}

AlfaRO, J. (1988) «Réflexions sur l'eschatologie de Vatican Il», en LATOURELL (1988), 533-545.

BORDEYNE, P. (2004) L'homme et son angoisse. La théologie morale de Gaudium et spes, París: Cerf.

Congar, Y. J.-M. y Peuchmaurd, M. (Dir.) (1967) L'Eglise dans le monde de ce temps: constitution pastorale «Gaudium et spes». Commentaires, T. 2 y 3, París: Cerf.

DE LUBAC, H. (1968) Athéisme et sens de l'homme: une double requête de "Gaudium et spes», París: Cerf.

DelHAYE, P. (1967) L'Eglise dans le monde de ce temps: constitution pastorale "Gaudium et spes». Texte latin et histoire des textes, T. 1, París: Cerf.

GagliaRd M. (Ed.) (2009) II mistero dell'incarnazione e il mistero dell'vomo: alla luce di Gaudium et spes 22, Città del Vaticano: Libreria editrice vaticana.

García Fernández, C. (2007) «La hermenéutica antropológica de la Gaudium et spes», en Burgense 48, 131-160.

Gertler, T. (1986) Jesus Christus: die Antwort der Kirche auf die Frage nach dem Menschsein: eine Untersuchung zu Funktion und Inhalt der Christologie im ersten Teil der Pastoralkonstitution «Gaudium et spes» des Zweiten Vatikanischen Konzils, Leipzig: St. Benno-Verl.

HaubtManN, P. (1967) «La communauté humaine», en Congar - Peuchmaurd (1967), T. 2, 255-278.

Heuín, G. (Ed.) (1985) Constitutionis pastoralis «Gaudium et spes» synopsis historica, Pamplona: Universidad de Navarra.

Herrera Oria, A. (Dir.) (1968) Concilio Vaticano Il: comentarios a la Constitución «Gaudium et spes» sobre la Iglesia en el mundo actual, Madrid: Biblioteca de Autores Cristianos. 
Karakunnel, G. (1984) The Christian vision of man: a study of the theological anthropology in "Gaudium et spes» of Vatican II, Bangalore: Asian Trading Corp.

KASPERS, W. (1986) «The theological anthropology of Gaudium et spes», en Communio 23, 129-140.

KIRCHHOFFER, D. G. (Ed.) (2013) Being human: groundwork for a theological anthropology for the 21 st century, Preston: Mosaic Press.

KreUtZER, A. (2006) Kritische Zeitgenossenschaft: die Pastoralkonstitution «Gaudium et spes» modernisierungstheoretisch gedeutet und systematisch-theologisch entfaltet, Innsbruck: Tyrolia-Verl.

LADARIA, L. (1988) «L'homme à la lumière du Christ dans Vatican II», en LAtourelle (1988), 409-422.

LAtOURelle, R., (Ed.) (1988) Vatican II. Bilan et perspectives vingt-cinq ans après (1962-1987), París: Cerf.

Mouroux, J., (1967) «La dignité de la personne humaine», en CongAR - PeUCHMAURD (1967), T. 2, 229-254.

RATZINGER, J. (1969) «The dignity of the human person», en VorGrimler, H., (Ed.) (1969) Commentary on the Documents of Vatican II, Londres: Burns \& Oates; Nueva York: Herder \& Herder, 115-164.

RULLA, L. M., IMODA, F., y RIDICK, J. (1988) «Aspects conciliaires et postconciliaires de l'anthropologie de la vocation chrétienne», en LATOURELLE (1988), 423-478.

Russo, R. (1983) Cristo nel mondo: la cristologia nella Costituzione Pastorale «Gaudium et Spes» del Concilio Vaticano II, Napoli: M. D'Auria.

SARTORI, L. (1995) La Chiesa nel mondo contemporaneo: introduzione alla "Gaudium e spes», Padova: Messaggero.

TANner, N. (2005) The church and the world: Gaudium et Spes, Inter Mirifica, Nueva York: Paulist Press.

THILS, G. (1967), «L'activité humaine dans l'univers», en Congar - Peuchmaurd (1967), T. 2, 279-304. 
TucCl, R. (1967a) «Introduction historique et doctrinale», en CONGAR - PEUCHMAURD (1967), T. 2, 33-127.

- (1967b) «La vie de la communauté politique», en CONGAR - PeUCHMAURD (1967), T. 2, 517-570.

TURBANTI, G. (2000) Un concilio per il mondo moderno: la redazione della costituzione pastorale "Gaudium et spes» del Vaticano II, Bologna: Il Mulino.

Verstraeten, J. (Ed.) (2007) Scrutinizing the signs of the times in the light of the Gospel, Leuven: Leuven University Press.

XAVIER, J. (2010) «Theological Anthropology of Gaudium et spes and Fundamental Theology», en Gregorianum 91/1, 124-136.

\subsection{Otras obras}

ARENDT, H. (1963) Eichmann in Jerusalem, University of Michigan: Viking Press.

GertLer, T. (1986) Jesus Christus: die Antwort der Kirche auf die Frage nach dem Menschsein: eine Untersuchung zu Funktion und Inhalt der Christologie im ersten Teil der Pastoralkonstitution «Gaudium et spes» des Zweiten Vatikanischen Konzils, Leipzig: St. Benno-Verl.

GORDON, C., (Ed.) (1980) Power and Knowledge: selected interviews and other writings 1972-1977, Michel Foucault, Nueva York: Panteon Books, 1980.

GuARDINI, R. (1950) Das ende der Neuzeit: ein Versuch zur Orientierung, Basel: Hess Verlag.

Ricoeur, P. (1986) «Le monde du texte», en Ricoeur, P. (1986) Du texte à l'action, Paris: Sevil, 111-117.

TAYLOR, Ch. (2007) A secular age, Cambridge, MA: Belknap. 